\title{
Social group and mortality in Finland
}

\author{
SIMO NÄYHÄ
}

From the Department of Public Health Science, University of Oulu, Finland

SUMMARY Mortality rates for various social groups within the population of Finland were compared, using 179919 death certificates for the period 1969-72. Mortality was generally lowest in the highest social groups and highest among unskilled workers. Male mortality from coronary heart disease was also high among lower salaried employees. In the less developed area of northern Finland, female mortality from coronary heart disease and vascular lesions of the central nervous system was highest among the agricultural population. Cancer of the breast, cancer of the intestine, and suicides among women were apparently concentrated in the higher classes. Life table analysis showed that the social group differences in life expectancy at birth could be as great as 7.2 years. It is considered indispensable for a national health policy to improve on the recording of occupational data and to give regularly the occupation of the deceased when publishing mortality rates.

The Finnish mortality rate is one of the highest in Europe and in the whole developed world. In 1970 the life expectancy at birth of a baby boy was 65.7 years and that of a girl 73.6 years, implying that a Finnish man dies on average three years earlier than an Englishman and as much as six years earlier than a Swedish man, the corresponding differences for women being approximately one year and 3.5 years (Vallin and Chesnais, 1974). Life expectancy is even shorter among the population of the less developed areas of Finland (Official Statistics of Finland, 1974).

This high mortality is partly a consequence of social factors and partly owing to a disregard for health care (Härö, 1966), yet the effect of general social and cultural factors on mortality has never been investigated thoroughly in Finland. The purpose of the present work is to examine the relationship between social status and mortality. This should be relatively easy as data giving the occupation for the population of the country are available at 10-year intervals from the census and the corresponding information is recorded on the death certificate. It is well known that the validity of this kind of investigation is impaired by differences between the occupation reported on the death certificate and that on the census return (Hauser and Kitagawa, 1960; Stockwell, 1961). However, the level of reliability is likely to justify statistical analyses being made using broad occupational grouping (General Register Office, 1958). Analysis of the data may, in any case, provide some useful information.
In this paper the mortality in different social groups within Finland is compared. The classifications were sex, age group, and cause of death; the details were taken from 179919 death certificates during the period 1969-72. In addition, calculations were made separately for the extensive northern part of the country, which is less developed than the rest. The study area is depicted in the Figure.

\section{Methods}

The term 'social group' was introduced into the census data for the first time in 1970, although it had been used in official statistics for 10 years before this. The classification is based upon the principal occupation of the respondent at the time of the census. Those no longer working are classified by their former occupation and dependants by the occupation of their supporter. Thus a married woman without any recorded occupation is classified by her husband's occupation, but by her own occupation if she is economically active. Children are classified according to their supporter's occupation. Widows are placed in the group indicated by their own occupation if possible, and otherwise in that corresponding to the occupation of their late husbands. For retired persons the grouping is that of former occupation.

The distribution of the population of Finland by social group in 1970 is presented in Table 1 (group VI was excluded from these calculations). The social groups differ from the social classification 


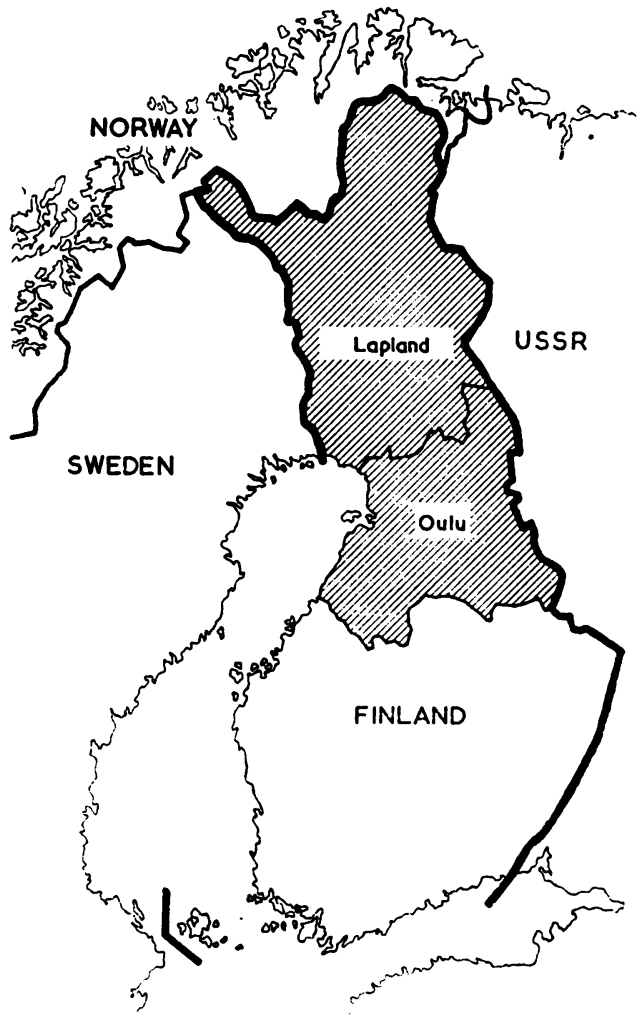

Figure The study area. Northern Finland (Lapland and the Province of Oulu) is shown hatched

Table 1 Finnish population by sex and social group in 1970

\begin{tabular}{|c|c|c|c|c|c|}
\hline \multirow{2}{*}{\multicolumn{2}{|c|}{ Social group }} & \multicolumn{2}{|l|}{ Men } & \multicolumn{2}{|l|}{ Women } \\
\hline & & No. & $\%$ & No. & $\%$ \\
\hline \multirow[b]{2}{*}{ II } & $\begin{array}{l}\text { Higher administrative or } \\
\text { clerical employees, and } \\
\text { employers comparable } \\
\text { with them, and persons } \\
\text { with academic degrees }\end{array}$ & 173694 & $7 \cdot 8$ & 167556 & $7 \cdot 1$ \\
\hline & $\begin{array}{l}\text { Lower administrative or } \\
\text { clerical employees and } \\
\text { employers comparable } \\
\text { with them }\end{array}$ & 367826 & $16 \cdot 6$ & 551514 & $23 \cdot 2$ \\
\hline \multirow{4}{*}{$\begin{array}{l}111 \\
\text { IV } \\
\text { V } \\
\text { VI }\end{array}$} & $\begin{array}{l}\text { Skilled or specialised } \\
\text { workers }\end{array}$ & 861417 & $38 \cdot 8$ & 747361 & $31 \cdot 4$ \\
\hline & $\begin{array}{l}\text { Unskilled workers, farm } \\
\text { and forestry workers } \\
\text { Farmers }\end{array}$ & $\begin{array}{l}256045 \\
389501\end{array}$ & $\begin{array}{l}11 \cdot 5 \\
17 \cdot 5\end{array}$ & $\begin{array}{l}290417 \\
406533\end{array}$ & $\begin{array}{l}12 \cdot 2 \\
17 \cdot 1\end{array}$ \\
\hline & $\begin{array}{l}\text { Students, pupils, or } \\
\text { social group unknown }\end{array}$ & 171502 & $7 \cdot 7$ & 214970 & $9 \cdot 0$ \\
\hline & Whole population & 2219985 & $100 \cdot 0$ & 2219985 & $100 \cdot 0$ \\
\hline
\end{tabular}

used by the Registrar General for England and Wales in that in Finland farmers are placed in group V, while according to the English ranking they would be classified as 'intermediate'. Farmers present a problem in the Finnish classification, as all farmers belong to group $V$, independent of the area they have under cultivation, whereas it is known that in Finland the actual social position of a farmer is closely correlated with the area of land he owns (Rauhala, 1966). Consequently, the social ranking used here is not exactly ordinal. Yet it is true that most farmers (about $75 \%$ ) are small farmers who usually own not more than 5-15 hectares of land, and who certainly are located in the lowest stratum in the social hierarchy. As will become obvious below, the present classification functions as an ordinal scale in less developed areas where the proportion of small farmers is even greater than elsewhere.

The social groups of the persons who died in Finland during the period 1969-72 were recorded by the Central Statistical Office of Finland using the occupational data on the death certificates, the classification being made in the same manner as in the 1970 census. The occupation and position of the deceased were entered on the death certificate by the doctor who treated the patient during his illness, and the data on occupation, position andeducation, were checked in the local population register offices. Monthly reports from the local $\stackrel{\odot}{\odot}$ registers were matched with the data on the certificates in the Central Statistical Office.

It was not possible to compare the occupation given by a person in the census with the occupation that appeared later on the same person's death certificate, but some idea of the accuracy? in recording this information may be obtained by comparing the proportions of those for whom the social group could not be determined because there was insufficient information. Table 2 shows that the proportion of 'indeterminate' cases was generally small, except for men aged 15-24 years, for whom the number of deaths was minimal. Although information seems to have been more often lacking on the death certificates than in the census, the data are sufficiently accurate to justify the present calculations.

In order to determine the effect of occupation, the death rates for the men were calculated without

Table 2 Percentages of persons for whom the social group remained unknown at the 1970 census or on death certificates in 1969-72

\begin{tabular}{|c|c|c|c|c|c|c|}
\hline & \multicolumn{6}{|c|}{ Age groups (years) } \\
\hline & $0-14$ & $15-24$ & $25-44$ & $45-64$ & $65-$ & All \\
\hline $\begin{array}{l}\text { Men } \\
\text { Census } \\
\text { Death certificate }\end{array}$ & $\begin{array}{l}1 \cdot 6 \\
3 \cdot 6\end{array}$ & $\begin{array}{l}1 \cdot 1 \\
6 \cdot 8\end{array}$ & $\begin{array}{l}0.7 \\
1.6\end{array}$ & $\begin{array}{r}1.0 \\
1.5\end{array}$ & $\begin{array}{l}1 \cdot 9 \\
2 \cdot 2\end{array}$ & $\begin{array}{l}1 \cdot 2 \\
2 \cdot 1\end{array}$ \\
\hline $\begin{array}{l}\text { Census } \\
\text { Death certificate }\end{array}$ & & $\begin{array}{l}0 \cdot 8 \\
2 \cdot 3\end{array}$ & $\begin{array}{l}0.4 \\
1 \cdot 5\end{array}$ & $\begin{array}{l}0 \cdot 9 \\
1 \cdot 5\end{array}$ & $\begin{array}{l}3 \cdot 3 \\
3 \cdot 5\end{array}$ & $\begin{array}{l}0 \cdot 8 \\
2 \cdot 5\end{array}$ \\
\hline
\end{tabular}


any division by civil status, whereas the calculations for the women were limited to married women only. The results were analysed using the age group 15-64 years in most instances, because:

1. The recording of the occupation at death is apparently more reliable for a person of active working age.

2. Mortality differences are presumably more obvious among the young and middle-age groups than among old people.

In those cases where a consistent distribution into social groups could not be observed or no significant departure from the average could be discerned, the death rates were calculated from the whole age scale and the total female population instead of just the married women. The rates were adjusted for age by an ordinary direct method using the Finnish male and female populations in 1970 as standard. In order to allow for random variation the standard errors of the rates were estimated by Poisson's formula.

In order to illustrate the mortality differentials more clearly, life tables were worked out for the male population using the abridged method (Barcley, 1958). Death rates for the population older than five years, $5 \mathbf{M}_{\mathbf{X}}$ ' in the age groups $(x, x+5)$, were obtained by dividing the number of deaths during 1969-72 by the population of the same age at the beginning of the year 1970 . The social group was taken from the death certificates and the census. For children under five years of age data could be obtained on social group for the age group 0 to 4 years only, but not separately for the ages 0 and 1 to 4 years. The following estimation procedure was therefore employed which appeared to be sufficiently exact. The proportions of boys aged 0 to 4 years were, from the highest to the lowest social group: $11 \cdot 4,21 \cdot 2,45 \cdot 0,8 \cdot 1,12 \cdot 1$, and $2 \cdot 2 \%$. The relative distributions were assumed to be the same among live births and among boys aged 1 to 4 separately. There were 129095 live births during 1969-72 and the number of boys aged between 1 and 4 years was 142042 in 1970. They were thus calculated to be distributed by social group as shown in Table 3.

Table 3 Social group for boys aged between one and four years

\begin{tabular}{lcc}
\hline Social group & $\begin{array}{c}\text { No. of live births, } \\
1969-72\end{array}$ & $\begin{array}{c}\text { Population aged } \\
1-4 \text { years, 1970 }\end{array}$ \\
\hline II & 14716 & 19193 \\
III & 27368 & 30113 \\
IV & 58092 & 63919 \\
V & 10456 & 11505 \\
VI & 15620 & 17187 \\
All & 2843 & 125 \\
\hline
\end{tabular}

For the ages between 1 and 79, the probability $n q_{x}$ that a person beyond the exact age $x$ will die before his $(x, x+n)$ th birthday was obtained by the formula

$$
{ }_{n} q_{x}=\frac{2 n{ }_{n} M_{x}}{2+n_{n} M_{x}}
$$

where $n$ denotes the length of the age interval.

The probability of death during the first year of life by social group was obtained by dividing the number of those who died before they were oneyear old during 1969-72 by the corresponding number of live births during the same period.

All persons were supposed to die not later than the age of 84 years, and thus the probability of death for ages between 80 and 84 was assumed to be exactly 1 .

For those older than one year of age, deaths were assumed to be distributed evenly between birthdays. Those who died at between the age of 1 and 4 years, thus produced 2.0 person-years during their life time, the corresponding figure being 2.5 personyears among males older than five years. For infants, it was calculated that all those dying before their first birthday, lived 0.0909 personyears on average. The figure was assumed to be approximately 0.1 in each social group.

\section{Results}

The probabilities of death for males in various social groups are presented in Table 4. The most striking observation is the poor status of social group IV compared with others. The figures for the first group, on the other hand, are below average for all ages except $15-24$, where a relatively high figure is found. More detailed analysis showed that this was mainly because of motor accidents. It is also apparent from Table 4 that the risk of death is greater for social group II than for either of the adjacent groups from age 45 up to the greatest age. For farmers the risk of death is above the average up to the age 30 years-except for the first year of life-but after this the figures are consistently below the average.

Age-adjusted indices by sex and cause of death are given in Table 5 . The figures reveal a relatively regular pattern of mortality from all causes and for most of the individual causes. The figures are generally lowest in the first social group, increase up to the fourth group and fall again for the fifth group, the farmers generally being on the better side of average. The differences between groups IV and I appear to be greatest among men and in 
Table 4 Average yearly probabilities of death per 1000 in different social groups for males

\begin{tabular}{|c|c|c|c|c|c|c|}
\hline \multirow{2}{*}{$\begin{array}{l}\text { Age group } \\
\text { (years) }\end{array}$} & \multicolumn{5}{|c|}{ Social group } & \multirow[b]{2}{*}{ Total } \\
\hline & $I$ & II & III & IV & $\boldsymbol{V}$ & \\
\hline $\begin{array}{c}<1 \\
1-4 \\
5-9 \\
10-14 \\
15-19 \\
20-24 \\
25-29 \\
30-34 \\
35-39 \\
40-44 \\
45-49 \\
50-54 \\
55-59 \\
60-64 \\
65-69 \\
70-74 \\
75-79\end{array}$ & $\begin{array}{r}10 \cdot 94 \\
0 \cdot 59 \\
0 \cdot 58 \\
0.27 \\
2.86 \\
1.76 \\
0.92 \\
1 \cdot 15 \\
2.25 \\
3.37 \\
5.55 \\
10 \cdot 40 \\
16 \cdot 49 \\
26 \cdot 44 \\
38 \cdot 87 \\
59 \cdot 37 \\
84 \cdot 49\end{array}$ & $\begin{array}{r}13.04 \\
0.87 \\
0.63 \\
0.35 \\
1.99 \\
1.41 \\
1.44 \\
2.08 \\
3.00 \\
5.05 \\
8.45 \\
13.84 \\
19.57 \\
30.01 \\
47.02 \\
67.82 \\
90.03\end{array}$ & $\begin{array}{r}15 \cdot 18 \\
0 \cdot 73 \\
0 \cdot 60 \\
0 \cdot 38 \\
1 \cdot 18 \\
1 \cdot 36 \\
1 \cdot 71 \\
2 \cdot 09 \\
3 \cdot 19 \\
5 \cdot 33 \\
8 \cdot 18 \\
12 \cdot 58 \\
19 \cdot 39 \\
28 \cdot 88 \\
41 \cdot 35 \\
58 \cdot 56 \\
77 \cdot 83\end{array}$ & $\begin{array}{r}20 \cdot 08 \\
1 \cdot 11 \\
0.73 \\
0.54 \\
2.24 \\
2.44 \\
4.07 \\
5.54 \\
8.05 \\
11.09 \\
14.43 \\
18.76 \\
26.47 \\
35.99 \\
51 \cdot 01 \\
69.82 \\
94.39\end{array}$ & $\begin{array}{r}12.16 \\
1.16 \\
0.71 \\
0.48 \\
1.71 \\
1.83 \\
2.02 \\
2.47 \\
3.27 \\
4.20 \\
7.55 \\
11.42 \\
17.95 \\
26.59 \\
39.48 \\
57.56 \\
81.71\end{array}$ & $\begin{array}{r}14 \cdot 61 \\
0.84 \\
0.65 \\
0.46 \\
1 \cdot 22 \\
1.49 \\
1.78 \\
2.39 \\
3.64 \\
5 \cdot 68 \\
8 \cdot 79 \\
13 \cdot 26 \\
19 \cdot 96 \\
29 \cdot 43 \\
43 \cdot 15 \\
61 \cdot 29 \\
83 \cdot 82\end{array}$ \\
\hline $80<$ & $1000 \cdot 00^{*}$ & $1000 \cdot 00^{*}$ & $1000 \cdot 00^{*}$ & $1000 \cdot 00^{*}$ & $1000 \cdot 00^{*}$ & $1000 \cdot 00^{*}$ \\
\hline
\end{tabular}

*Assumed value

respect of pulmonary tuberculosis, diseases of the respiratory organs, drowning, and suicides. The differences are of smaller magnitude for women. Most of the individual causes of death reveal a trend similar to that for total mortality, although the following exceptions deserve attention:

1. Mortality from cancer of the breast, cancer of the prostate, cancer of the intestine, leukaemia in males, and diabetes seems to be concentrated in the higher social classes.

2. Male mortality from coronary heart disease follows roughly the usual pattern, but a high figure is found in the second social group. This feature is repeated in the data for northern Finland alone.

3. Mortality from coronary heart disease and vascular lesions of the central nervous system among northern Finnish women is highest not in group IV but in group V.

4. Suicides in men follow the usual distribution, whereas suicides in women seem to be concentrated in the higher social groups.

The expectation of life in the male population by age and social group is presented in Table 6. The difference in life expectancy at birth between the fourth and the first group is $7 \cdot 2$ years, and it is still $2 \cdot 1$ years at the age of 55. The second group, too, is somewhat below the average.

Table 6 Expectation of life for Finnish males by age and social group in 1969-72

\begin{tabular}{|c|c|c|c|c|c|c|c|}
\hline \multirow{2}{*}{$\begin{array}{l}\text { Age } \\
\text { (years) }\end{array}$} & \multicolumn{5}{|c|}{ Social group } & \multirow{2}{*}{$\begin{array}{l}\text { Total } \\
\text { male } \\
\text { population }\end{array}$} & \multirow{2}{*}{$\begin{array}{l}\text { Difference } \\
\text { between } \\
I \text { and IV }\end{array}$} \\
\hline & $I$ & II & III & IV & $\boldsymbol{V}$ & & \\
\hline $\begin{array}{r}0 \\
15 \\
35 \\
55\end{array}$ & $\begin{array}{l}67.5 \\
53.7 \\
35.3 \\
17.8\end{array}$ & $\begin{array}{l}\mathbf{6 5 . 5} \\
51.8 \\
33.3 \\
16.8\end{array}$ & $\begin{array}{l}66.1 \\
52.6 \\
34.0 \\
17.4\end{array}$ & $\begin{array}{l}60 \cdot 3 \\
47 \cdot 2 \\
29 \cdot 9 \\
15 \cdot 7\end{array}$ & $\begin{array}{l}66 \cdot 3 \\
52 \cdot 8 \\
34 \cdot 6 \\
17 \cdot 8\end{array}$ & $\begin{array}{l}65.5 \\
52 \cdot 0 \\
33 \cdot 5 \\
17 \cdot 2\end{array}$ & $\begin{array}{r}+7.2 \\
+6.5 \\
+5.4 \\
+2.1\end{array}$ \\
\hline
\end{tabular}

\section{Discussion}

\section{METHODS}

It may be questioned whether the occupation give on death certificates is as reliable as it is on the $\underset{\varnothing}{\varnothing}$ census. The census is instituted by law and is carrieg out in a manner likely to give reliable results, whereas $\subseteq$ information on the death certificate is given by the $\overrightarrow{0}$ widow or other informant and in a situation i which the occupation of the deceased is of mine importance. According to the current regulations at doctor is obliged to enter on the death certificate 'exact information on the occupation and field of

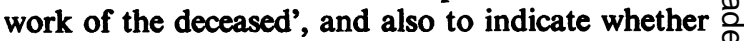
the occupation mentioned is that of the deceased, or $\stackrel{\mathbb{Q}}{\square}$ the spouse or the supporter, or whether it was $\overrightarrow{\overrightarrow{0}}$ formerly that of the deceased. There are no detailed 3 instructions, however, on whether the statement must refer to the last occupation or to that in which the deceased worked for most of his life. In the census a person may be inclined to give $\stackrel{\odot}{)}$ information which will elevate his status, and the same tendency is likely to exist among the relatives of the dead when giving the required $\delta$ information to the doctor. There is a tendency to elevate one's status in both situations (General 을 Register Office, 1958), but it is more pronounced in relatives at death than for the person himself in the census. If this is true for the present material, more deaths should be concentrated in the higher or social groups than is the actual case, while the $N$ figures for the lower groups may be too low. The differences between the groups may thus be even $\sigma$ greater than could be concluded from the figures 0 presented here. 


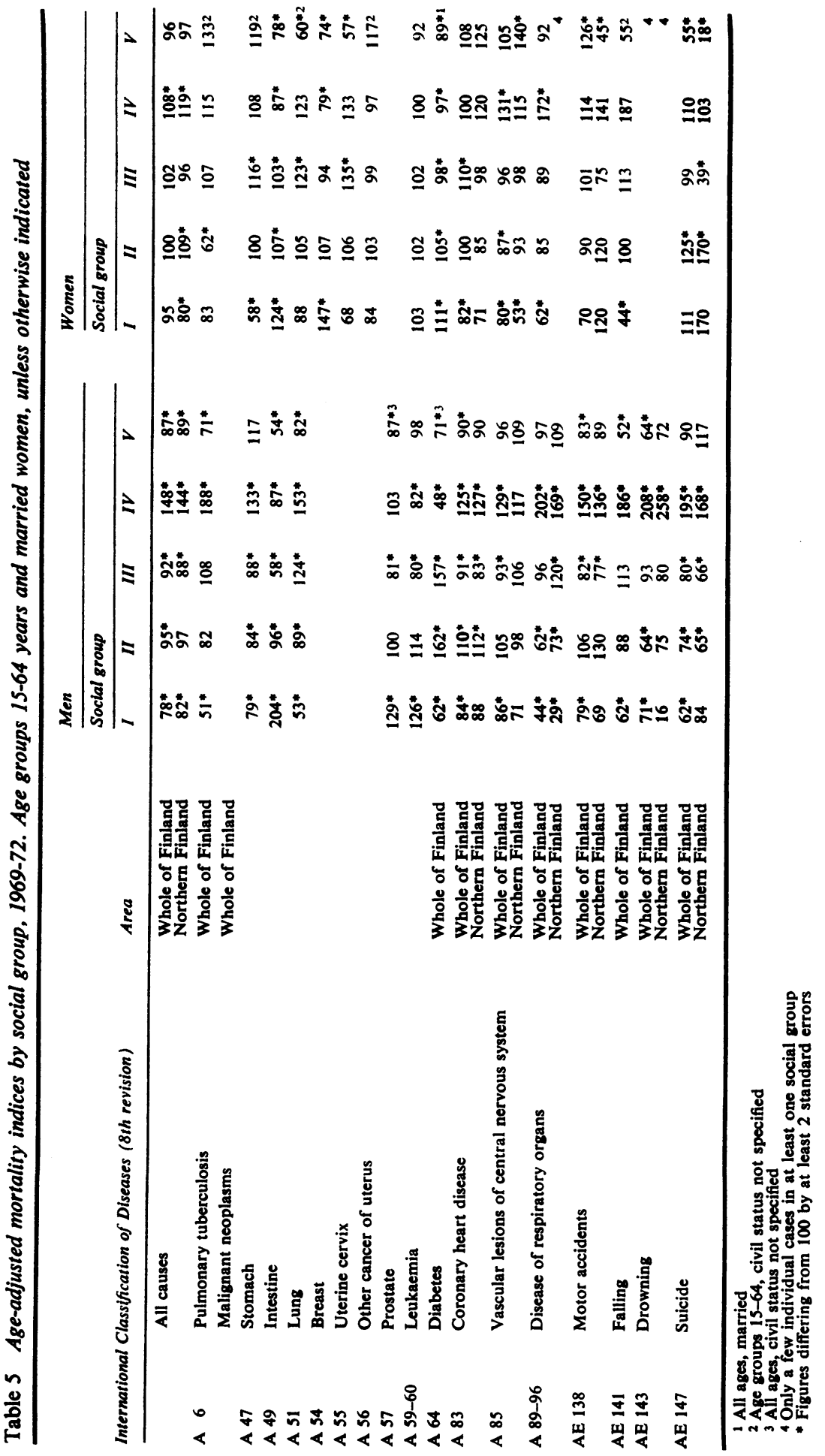

3

음

$\stackrel{\vec{F}}{\stackrel{9}{+}}$

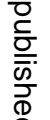

๓

o

ज़

$\stackrel{\omega}{\omega}$ 
The fact that the social group could be determined in nearly all cases from both the census and the death certificate suggests that the material is reliable enough to give reasonable results. As the Registrar General stated, discrepancies between the occupation reported on the death certificate and that on the census return may be serious in individual cases, but do not result in essential net errors when a broad occupational grouping is used (General Register Office, 1958). There is no reason to believe that circumstances are otherwise in Finland, although naturally it is desirable that the occupation in the census should match that of the death certificate in this country, too.

\section{RESULTS}

The distribution of deaths by social group is broadly similar to that observed in other countries. It is not possible here to undertake international comparisons by cause of death, however interesting this might be, for such comparisons may be of dubious validity, partly because of differences in social classifications. This type of investigation is only a crude instrument for assessing occupational risks. Detailed information must be acquired by more specialised research in which the nature of the material and any complicating factors can be adequately appreciated. Certain comments warrant mention at this juncture, however.

The main observation seems to be the poor outlook for unskilled workers. Very similar results have been reported elsewhere (Logan, 1954; Tabah, 1955; Ledermann, 1960; Benjamin, 1965). It appears from Table 4 that the risk of death for these people is above average in each age group and the difference is many times greater in young adults. The discrepancy of seven years in life expectancy at birth is greater than the difference between the whole Finnish male population and the Swedish males. Mutual differences between other social groups are of moderate magnitude as compared with those between the two extreme groups. The figures in group IV are not likely to be artificially inflated, but the contrary may be true: it is very possible that the number of deaths in group IV may be artificially low due to the fact that unskilled workers are recorded either as skilled workers or as farmers. The occupation of farmer is traditionally an honourable one in Finland, and it is probable for example, that a dead person may be classified by his relatives as a farmer rather than as a general labourer. This may be true despite the fact that farming has been shown to be generally poorly appreciated in terms of economic status in this country (Rauhala, 1966).

We also know that the prevalence of sickness and injury is greatest in 'occupations that require the least amount of occupational competence' (Purola et al., 1974). Whether the high risk of death is mainly due to selection, unhealthy mode of living, or unwillingness to consult a doctor remains unknown, however.

Mortality from coronary heart disease is particularly common among unskilled workers. This observation does not agree with the idea that the disease is more prevalent in the higher social classes (Inghe, 1973). However, a high mortality is also found among the lower salaried employees, which is repeated in almost exactly the same way in the results for northern Finland alone and is reflected in total mortality. The high risk of death in social group II from the age of 45 years upwards (Table 4) is thus due to coronary heart disease. As no corresponding peak is observed among women, this feature may well be occupational in origin. The lower salaried employees are probably those who have risen from the lower social classes during this period of social change and urbanisation, and this rise has proved fatal.

One special feature of the less developed northern part of the country can be considered to be the poor position of the farmers' wives with respect to mortality from coronary heart disease and vascular lesions of the central nervous system. The phenomenon may reflect the situation in the underdeveloped areas of the country facing depopulation, where the poor living afforded by farming has forced some of the men to earn extra income elsewhere, placing the burden of the agricultural work upon the women.

More accurate diagnosis is likely to account for the higher death rates from leukaemia and cancer of the prostate in the higher social groups. Mortality from cancer of the breast and cancer of the intestine agrees with previous reports (Inghe, 1973). The high number of suicides among women in the higher groups may be explained by the fact that the social standing of women is more likely to be affected by the crises of life, such as the loss of spouse, than that of men.

\section{CONCLUSIONS}

The results indicate that in spite of the highly developed health care system in Finland, mortality differentials between the social groups are considerable. One cannot be positive that the high mortality of the Finnish people is exclusively a con- 
sequence of social circumstances. It can, however, be calculated that if the overall mortality of the population equalled that of the higher classes, the Finns would be at an average level in the European mortality statistics. The consistently poor outlook for unskilled workers shows that the life of this group has risk factors to which especially great attention should be paid. The relationship between social standing and mortality is complicated, however, and apparently varies in different parts of the country. The recording of occupational data within the health care system is still imprecise, and the results presented here may include errors inherent in the material. It would be necessary to improve the recording of occupational and educational data both in the official statistics and in the health centres, preferably in a manner conforming with international practice.

I am indebted to the Statistical Office of Finland and its personnel for providing the material for this work.

Reprints from S. Näyhä, Department of Public Health Science, University of Oulu, 90220 Oulu 22, Finland.

\section{References}

Barcley, G. W. (1958). Techniques of Population Analysis, p. 286. Wiley: New York.

Benjamin, B. (1965). Social and Economic Factors Affecting Mortality. Mouton: Paris.
General Register Office (1958). Census 1951, England and Wales, General Report. HMSO: London.

Härö, S. (1966). Kuolleisuus Suomessa ja muissa pohjoismaissa 1948-1964. Duodecim, 82, 1136-1151.

Hauser, P. M., and Kitagawa, E. M. (1960). Social and Economic Mortality Differentials in the USA 1960: Outline of a Research Project. Proceedings of the Social Statistics Section, p. 116. American Statistical Association: Washington DC.

Inghe, G. (1973). Socialmedicin, volume 1, p. 221. Scandinavian University Books: Stockholm.

Ledermann, S. (1960). Estimation de l'espérance de vie à la naissance par catégorie professionelle en France. Population (Paris), 15, 127-131.

Logan, W. P. D. (1954). Social class variations in mortality. British Journal of Preventive and Social Medicine, 8, 128-137.

Official Statistics of Finland (1974). Life Tables 19661970. Central Statistical Office of Finland: Helsinki.

Purola, T., Kalimo, E., and Nyman, K. (1974). Health Services Use and Health Status under National Sickness Insurance, p. 236. The Social Insurance Institution: Helsinki.

Rauhala, U. (1966). Suomalaisen yhteiskunnan sosiaalinen kerrostuneisuus. Werner Söderström Osakeyhtiö: Helsinki.

Stockwell, E. G. (1961). Socioeconomic status and mortality in the United States. Public Health Reports, 76, 1081-1086.

Tabah, L. (1955). La mortalité selon la classe sociale. Le Concours médicale, 77, 2839-2846.

Vallin, J., and Chesnais, J. C. (1974). Evolution récente de la mortalité en Europe, dans les pays anglo-saxons et en Union Sovietique. Population, 29, 861-898.

World Health Organisation (1967). International Classification of Diseases, 8th revision. WHO: Geneva. 